\title{
A.JOTE
}

African Journal of Teacher Education

ISSN 1916-7822. A Journal of Spread Corporation

Volume 10. No. 12021 Pages 70-86

\section{Post-secondary Entrance Examinations in Nigeria: A Critical Analysis of the Design and Predictive Validity of the Tripartite Assessment System}

\author{
Monsurat Omobola Raji \\ Faculty of Education \\ University of Ottawa, Canada
}

\begin{abstract}
Admission into post-secondary education requires the fulfillment of specific standards or criteria by prospective candidates. Criteria include, but are not limited to, standardized examinations, resumes, intent statements, tests, interviews, etc. In Nigeria, prospective students must pass three examinations as part of the admission process into post-secondary programs. Reports suggest these examinations lack the best design features and have very low predictive validity in student success in post-secondary programs and their job roles after graduation. This paper critically evaluates the design features of SSCE, UTME, and PUTME in the context of Nigeria and their predictive validity towards student learning and success as graduates. Implications of the Nigerian post-secondary entrance assessment system are discussed. Recommendations are offered from two jurisdictional models to improve the current status of the tripartite postsecondary entrance assessment system in Nigeria.
\end{abstract}

Keywords: Assessment, post-secondary education, admission, Nigeria, graduates

\section{Introduction}

Education holds an essential value in the development of an economy, jurisdiction, or country. Post-secondary education significantly accounts for the skill level of graduates who are either 
prepared or unprepared for employment (Holden, Kitchen, Petrarca, \& LeSage, 2016). A postsecondary degree or certificate acquisition process entails securing entrance into programs and satisfying the requisite requirements stated for the program. World over, admission into postsecondary programs require the fulfillment of specific standards, albeit differently for several programs and education systems. Most times, prospective students are required to write tests, submit personal statements, or have some volunteer experiences to meet up with set standards of programs of interest.

In Nigeria, prospective students must fulfill set standards to secure entrance into postsecondary education (e. g., universities, colleges, and polytechnics). These standards include expectations for students to score high marks on three standardized examinations. These examinations: Senior Secondary Certificate Examinations (SSCE), Universal Tertiary Matriculation Examinations (UTME), and the Post-UTME are summative in design and purpose. The West African Examinations Council (WAEC) and the National Examination Council (NECO) are regulatory bodies that organize SSCE for students in the third year of senior secondary schools in Nigeria. Students may sit for either WAEC or NECO examinations to obtain the senior secondary school certificate. The Joint Admissions and Matriculations Board (JAMB) oversees the conduct of the UTME. In contrast, individual post-secondary institutions conduct PUTME for students with minimum set grades and scores in SSCE and UTME, respectively.

The need for students to pass three qualifying examinations arose from the necessity to admit duly qualified candidates into Nigerian post-secondary institutions and graduate competent students. For example, the UTME was established to respond to education stakeholders' reports on issues related to "multiple applications and admissions as well as the absence of standardization in addition to lack of uniformity in admission guidelines" (Emaikwu, 2015, p. 55) that plagued Nigerian post-secondary institutions. Similarly, the PUTME was introduced from an observed intake of poorly qualified students admitted into Nigerian post-secondary education due to incessant examination malpractices reported from UTME (Ebiri, 2010). Examination malpractice is a negative implication of relying on SSCE and UTME to admit students into postsecondary programs (Emaikwu, 2015). Therefore, students' grades on each of these standardized examinations (WAEC/NECO, UTME, and PUTME) form components used to categorize, rank, and stratify students into post-secondary programs in Nigeria. 
According to Brown (2017), a standardized test is a "test which has been designed to be administered and scored according to specified rules; usually relies on selected-response items and generates norm-referenced scores to aid interpretation" (p. 132). This definition tallies with the senior secondary examinations' design and scoring (WAEC and NECO), UTME and PUTME, and their utilities in ranking students for post-secondary entrance. Standardized assessments, especially those classified as objectively scored, are usually easy to grade, involve limited influence from the marker, allow students to answer more questions within a stipulated time, and are generally perceived as a fair process of evaluating what students know (Brown, 2017). However, Brown mentions that the content of most standardized examinations is superficially relevant to curriculum outcomes, does not measure students' deep understanding and learning, and usually, grade interpretation for most standardized tests is problematic.

The purpose of this paper is to critically analyze the design and efficacy of the tripartite examinations required for post-secondary entrance into Nigerian institutions. By design, I intend to showcase the types of assessment questions designed for students taking those examinations. Standardized assessments may take the form of a selected-response or constructed-response item type (Brown, 2017). Efficacy-wise, I present a critical review of literature on the predictive validity of entrance tests/examinations towards students' postsecondary learning and future performance in real-life work settings as graduates (especially teachers).

Extant literature has compared the relationship between students' grades in entrance examinations and how they perform during their undergraduate programs (Abdulkadir \& Ogwueleka, 2019; Busayo, 2010; Ngozi \& Ugochukwu, 2018). Besides, other studies detail the predictive validity of entrance examinations or grades on graduates' requisite competencies and skills required to perform efficiently in work settings (Casey \& Childs, 2011; Chao, Sung, \& Huang, 2019; Holden et al., 2016; Oluwatayo, Adirika, \& Wodi, 2014; Shodipo, 2014). These studies argue that for most students, standardized tests measuring only cognitive abilities do not provide institutions with opportunities for selecting suitable candidates who can satisfy program requirements. Similar assertions were recorded in studies that explored Nigerian students' educational achievement in post-secondary programs (e. g., Abdulkadir \& Ogwueleka, 2019; Ngozi \& Ugochukwu, 2018). A common idea shared by these studies are the inadequacies associated with the tripartite post-secondary entrance assessment system 
Post-secondary Entrance Examinations in Nigeria: A Critical Analysis of the Design and Predictive Validity of the Tripartite Assessment System

currently employed in Nigeria. This assessment system neither contributes towards increased student learning in post-secondary education nor performance in job roles upon graduation (Oluwatayo et al., 2014).

For example, Abdulkadir and Ogwueleka's (2019) study conducted a predictive validity of the tripartite examinations on 943 first-year students in Northern Nigeria. The study found that the three entrance examinations did not influence first-year students' academic achievement as observed from their first-year academic records. These authors conclude that Nigeria's tripartite entrance assessment system lacks efficacy in preparing students for post-secondary education learning and success. Besides, through personal readings on standardized assessment and my experience of the three assessments within the Nigerian education system, I sought to find answers to some pertinent questions about using the tripartite assessment system, which appears as highly cognitive. Do these examinations probe critical thinking and procedural knowledge in students? Does it, in any way, empower them for future learning in postsecondary education? As Brown (2017) contends, the framework adopted in the design of assessment items has implications on the test's efficacy, students' university grades, the jobs that graduates will seek, and how they can perform the roles assigned to them in those jobs.

Considering the above discussions, I found the necessity to explore the validity of utilizing the tripartite assessment system as an entrance criterion into Nigerian post-secondary institutions. One of the significances of this paper is the opportunity it affords educators (and other readers) a detailed description of each of the examination's design. Whereas previous studies (mostly empirical) focused relatively on one or two of the three examinations, I present an overview of the three examinations. Hence, this study adds to ongoing discussions on the efficacy of using the tripartite system of assessment. Further, it contributes to the need for a holistic overhaul of Nigeria's post-secondary entrance assessment system. Also, it presents recommendations from two case studies (Canada and Taiwan) on the use of both cognitive and non-cognitive assessment models as entrance criteria into post-secondary education.

To guide the reader through the upcoming sections in this paper, I first present a brief overview of assessment policies existing at all education levels in Nigeria. I then present an analysis of each examination's design features by reviewing available policy and assessment documents to showcase their assessment framework and how this framework supports learning 
for students. Furthermore, I provide a literature review on the three examinations' predictive validity on post-secondary students' learning and achievement. Following a critical analysis and review of pertinent studies, I find it necessary to discuss models utilized in other education jurisdictions regarding post-secondary entrance assessment designs to enumerate contextual differences. Therefore, recommendations from two case studies are provided. The paper concludes with suggestions and the necessity to review the current assessment criteria used in selecting students into Nigerian post-secondary education.

\section{An Overview of Assessment in the Nigerian Education System}

The Nigerian Policy on Education mandates nine years of compulsory schooling for all citizens: six years of elementary education and three years of middle school education (Federal Ministry of Education, 2004). Students attend three years of senior secondary education, and interested students proceed to post-secondary education. Assessment of students after the mandatory nineyear education mainly relies on summative assessment with limited use of formative assessment. Students are mandated to take a standardized examination for promotion to senior secondary schools. A similar process is engaged for senior secondary school completion examinations, whereas in this case, the intent is for certification and post-secondary entrance.

Assessment in Nigerian schools is generally summative as teachers teach and assess students purposefully to pass external and compulsory examinations. This way, schools are ranked higher and are highly sought after by parents. On the contrary, contemporary assessment discourses have frowned against such accountability measures. Students' knowledge and understanding are not reflected through high scores on achievement tests but through individualized and authentic assessment processes that can indicate a realistic progression in their learning (Brown, 2017).

It is essential to mention that the above assertion is not intended to relegate summative assessment and achievement tests as unimportant assessment types. Indeed, both assessment types are often implemented in contemporary assessment practices, but teachers and educational stakeholders need to be cautious of the intended purpose for use. Other concerns relate to how information derived from standardized assessments is utilized. Implications of the use of standardized test results could influence students' "access to schools, special educational programs, scholarships, jobs, and promotions" (Zwick \& Doran, 2016, p. 267) and identity 
formations (Brown, 2017). As a recommendation for improving test efficacy, Brown (2017) mentions that the content and design of tests must measure important curriculum outcomes and be written in clear terms and language appropriate to the students taking such tests. Hence, the next section of this paper touches on the design of each of the tripartite examinations required for entrance into Nigerian post-secondary education.

\section{Senior Secondary Certificate Examinations (SSCE)}

Students in the final year of secondary school (grade 12) are required to write either the West African Certificate Examinations (WAEC) or the National Examination Council (NECO) to obtain a senior secondary school certificate. For about two decades, reports document incessant students' failures in these examinations, especially in Mathematics and English language. For example, after an evaluation of the results of the 2013 SSCE by WAEC, the examination body published that:

The results of candidates in the Senior Secondary School (SSC) examinations conducted have been that of mass failure in recent years. The situation has become a source of worry to many Nigerians, as well as to the examination body that conducts the exam (Information Nigeria, 2013, n. p.).

Thus, only $37.97 \%$ of students who sat for the 2013 SSCE obtained a credit grade and above in five subjects, including mathematics and English language; in 2014, this figure declined to $31.28 \%$ (Amuche, Amuche, Bello, \& Marwan, 2014). To secure a place in a university program in Nigeria, students must obtain a $\mathrm{C}$ grade in at least five required subjects for their chosen program. From 2008 to 2011, students' results for the SSCE revealed an average failure rate of 72, 74, 74, 75 percent, respectively (Osuagwu, 2011).

The above statistics reflect student failures in these examinations and the percentage of students who may probably get admitted into post-secondary education. In response to the yearly failure rate, SSCE examining bodies issued a communique on perceived factors responsible for student failures. They mentioned that students fail due to "shallow knowledge of the subject matter, poor command of the use of English language, poor knowledge of the examination techniques, as well as disregard for correct interpretation of questions before attempting them" (Information Nigeria, 2013). Although students, teachers, parents, and examining bodies have a role in ensuring that students meet up with standards set for the examination, the examining 
body has a more significant and active role in student failures, specifically through the design of the examination questions.

From a critical perspective, this paper will review SSCE questions within the scope of the number of multiple-choice questions (MCQ) options (key and distractors) and the functionality of distractors in the options provided for students. To limit the possibility of guessing by students, the suggested number of MCQ options should be set to four or five (Brown, 2017). Traditionally, WAEC and NECO have always provided four and five options, respectively, for each item on their examinations; this implies they both have an excellent discrimination power (Owolabi et al., 2017). The functionality of test item options relates to how plausible distractors (wrong options) are in drawing the attention of test-takers from the key (correct answer) (Owolabi et al., 2017). In a comparative study of the 2015 WAEC and NECO English Language examination options, Owolabi and colleagues found that $87.2 \%$ of WAEC options and $53.6 \%$ of NECO options are functional. The above statistics indicate that for MCQ sections in these exams, it is less likely for students to choose a correct answer by chance in WAEC, increasing the validity of such tests (Brown, 2017).

Recently, SSCE provided opportunities for prospective students to view the exemplars of tests and rubrics through designated platforms. In addition, the design of the SSCE incorporates multiple-choice questions with problem-based questions and laboratory-based questions. Given these, it is critical to note how SSCE bodies attempt to provide different assessment designs and better opportunities for students to prepare for the examinations through exemplars. However, SSCE only forms a part of the components required for university admissions.

\section{Universal Tertiary Matriculation Examinations (UTME)}

Another major requirement for admitting students into post-secondary education in Nigeria is to attempt and obtain above the yearly cut-off grade in UTME. Over the years, students (myself inclusive) have experienced challenges before and during this examination. Often, students experience tension, fatigue and low self-esteem when they do not meet the cut-off mark (usually set at a minimum of 180/400 in most cases). In terms of its design, this exam was changed from paper-based to a purely computer-based test $(\mathrm{CBT})$ in response to a high examination malpractice rate. However, for most Nigerian students, technology in schools tends to be a luxury since there are limited facilities to engage students in using technology for assessment. Limited technological 
skills further increase the stress and anxiety experienced by some students while writing the UTME. Since the inception of CBT design in 2015, significant issues have affected students' success in the examination. Some challenges observed include the inadequate technological capacity to develop students' information and technology (IT) skills; inadequate electricity supply experienced in all Nigerian cities; and students' limited IT skills (Ogechukwu, 2019).

In addition to being purely CBT-based, another design feature of the UTME is its multiple-choice question (MCQ) format. Although UTME is significant in the process of securing a spot in Nigerian post-secondary programs, the reliance on MCQ design tends to limit its efficacy towards contributing to student learning and academic progress in post-secondary education. A significant disadvantage of examining students through MCQ is its inability to measure students' in-depth understanding (Brown, 2017). Furthermore, UTME questions being exclusively MCQs seem to eliminate the need to connect assessment with the reality of everyday life experiences that can improve student learning (Brown, 2017). Whereas one of the goals of assessment is to develop students' critical thinking and procedural knowledge as linked to real-world situations (Brown, 2017), the UTME appears to foster a disconnect with real-life situations by designing only MCQs.

For example, in science-related disciplines, the use of online MCQs is challenging for students, especially with problem-solving calculations (Terblanche, 2017). This author argues that provisions should be made for students to demonstrate their knowledge of a topic through constructed-response questions (CRQ), as is the case in the SSCE part B questions. Other methods of measuring outcomes using MCQs will require immediate formative feedback to students by the examination body (Terblanche, 2017). However, as stated earlier, the UTME examination is solely MCQ designed and does not provide students with formative feedback. Research reports that adopting only MCQ assessment design and focusing questions on memorizing facts have negative implications on students' performance in such tests (Brown, 2017) and limit the examination's efficacy in assisting students' future learning (Terblanche, 2017).

Another implication resulting from the design and focus of questions in the UTME is the upsurge of examination malpractice. Historically, because UTME has contributed towards increased stress levels for most students and their families, some students have lost the courage to pass the exam, and students' identities have been negatively affected. Hence, student and 
parental engagement in misconduct have heightened in a bid for high scores. Emaikwu (2015), for example, noted disappointing and frightening cases of students', parents', and examination officials' involvement in examination malpractices in the Nigerian education system. Furthermore, the 2020 JAMB policy meeting report provides evidence of student engagement in examination malpractices. The examination body reports on how students and examination officials indulge in the act of examination malpractice. Additionally, the number of examination malpractice cases discovered in the 2019 UTME was 16,586 (JAMB, 2020). The examination body has since devised strategies to curb examination malpractice in the UTME.

\section{Post-Universal Tertiary Matriculation Examinations (Post-UTME)}

Responding to several complaints and criticisms regarding the design and utility of the UTME for post-secondary entrance, the Nigerian government introduced another assessment policy whereby students that scored above the minimum grades in SSCE and UTME will be invited for screening by the student's institution of choice. This policy mandates post-secondary institutions to conduct internal examinations in addition to the ones reviewed in previous paragraphs. Again, this examination engages either a paper-based or CBT design, depending on the institution's technological prowess. Since the inception of the PUTME, most institutions have relied on the MCQ assessment design. In contrast, some institutions (especially those using paper-based design) have included an essay section in their assessment design. In both cases, tests have focused on the student's intended discipline. The inefficient coordination, favoritism, and malpractices recorded from this examination have placed it under severe scrutiny from stakeholders in recent years. Besides, studies have revealed inconsistencies in students' test scores in UTME and PUTME despite that they both assess students on their intended subjects of choice. To establish possible validity differences between the two examinations, Emaikwu (2015) and Busayo (2010) found that some students who passed the UTME failed PUTME.

To explore the validity of PUTME in ensuring that unsuitable students are not admitted into post-secondary programs, Busayo (2010) sampled the results of 200 candidates who applied to a teacher education program in western Nigeria after scoring 200 and above in UTME. Results revealed that only $43.5 \%$ of the students scored above $40 \%$ in the constructed response questions (CRQ) section of the examination designed to screen candidates based on their writing skills. Busayo's (2010) study implies that without PUTME, all 200 candidates would have secured 
admission into the teacher education program, with $56.5 \%$ of candidates possessing limited writing skills $-\mathrm{a}$ vital requirement for the program. This finding suggests that CRQ design provided the requisite information about prospective candidates' skill level to the teacher education program. Busayo (2010) concludes that in addition to UTME, PUTME should be included in the criteria for seeking admissions into post-secondary programs in Nigeria. In terms of assessment design, both MCQ and CRQ should be incorporated in the PUTME (Busayo, 2010). However, in most institutions currently, MCQs are widely used because of the increasing candidate population seeking entrance into Nigerian post-secondary institutions (Emaikwu, 2015).

Overall, implementing MCQs is advantageous as it limits marker influence; therefore, it is considered more objective. However, it encourages memorization of facts, does not provide information on the students' skill sets, and often does not offer feedback opportunities for students' future learning (Brown, 2017). Implications of the reliance of examining bodies on MCQ test design are observed in the heightened examination misconducts recorded in the Nigerian tripartite assessment system. Even the SSCE that provides exemplars for students and designs assessment sections with CRQs has been faulted based on its limited focus on assessing students' critical thinking skills (Emupenne, 2017). Indeed, the tripartite system of evaluating students' suitability for post-secondary education in Nigeria has been holistically ineffective. Given that one of the underlying assumptions for entrance examinations into post-secondary programs is to predict students' suitability and performance in those programs, it is crucial to present findings from studies on the relevance of these three examinations to student learning in their program of study and after graduation.

\section{Implications of Entrance Systems on Post-secondary Graduates' Achievement and Performance}

Implications of standardized tests should not only be viewed through the content validity and suitability in selecting students into programs but through its predictive validity in ensuring future achievement for students. One way to test the efficacy of large-scale standardized tests is to provide students with opportunities for future learning, which has been explored through the predictive value of such tests. In the last decade, Nigeria has recorded a decline in the achievement 
and learning of post-secondary students. This decline cannot be separated from the assessment and admission process or criteria employed in admitting students into programs (Emaikwu, 2015).

In a study of 943 faculty of science students (computer science, mathematics, and physics) in Northern Nigeria, Abdulkadir and Ogwueleka (2019) sought to predict first-year undergraduate students' GPA from the scores obtained from the three entrance examinations (SSCE, UTME, and PUTME) used to select candidates into the programs. These authors found a correlation of 0.068 with a statistical significance of 0.04 between students' scores in SSCE and GPA, but no correlations between GPA and the other two examinations (UTME and PUTME). Results from Abdulkadir and Ogwueleka's study suggest that only SSCE predicted students' GPA in their first year of the science programs investigated. The study concludes that UTME and PUTME are not relevant in providing students with future learning opportunities, especially those required for post-secondary programs. Abdulkadir and Ogwueleka (2019) recommend reviewing assessment policies used to select students into post-secondary programs in Nigeria.

Similarly, Njoku and Ugochukwu (2018) investigated the predictive validity of PUTME on 389 final-year students' results in five departments in a southern Nigerian university. These authors argue that internally designed post-secondary entrance tests could affect students' achievement in their programs. Hence, they found the need to establish if PUTME mainly influences students' final grades in post-secondary programs. In Nigeria, students' cumulative grade point average (CGPA) represents "the product of the grade point and credit hours for each course taken in the current and all previous semesters divided by the total number of credit hours taken in the current and all previous semesters" (Njoku \& Ugochukwu, 2018, p. 41). Findings revealed that in four of the five departments investigated, students' PUTME scores did not predict their final-year CGPA (Njoku \& Ugochukwu, 2018). These authors recommend the inclusion of departmental interviews as part of the screening criteria for students' admission into postsecondary programs in Nigeria.

In terms of providing graduates with essential skills and competencies required in their job roles, Holden et al. (2016) argue that "beyond their utility as a gatekeeping practice, admission standards also shape the future of the profession" (p. 4). For Nigerian students, research attributes students' inadequacies after graduation to the flawed admission process in selecting them into 
post-secondary programs. This issue arose from ongoing failures recorded from Nigerian graduates' inability to meet job expectations (Emaikwu, 2015; Shodipo, 2014).

The development of graduates' soft skills needs to be enforced before their post-secondary entrance (Shodipo, 2014). However, for most Nigerian students, early, middle, senior and postsecondary education have failed to provide such opportunities due to inadequate facilities in most Nigerian schools (Emaikwu, 2015). Additionally, the design features of the tripartite system of post-secondary entrance assessment in Nigeria provide limited opportunities to assess critical thinking, higher-order thinking, and information technology skills for most candidates. Notably, if the primary purpose of education is to prepare students to become successful graduates, then the post-secondary education entrance criteria must be highly effective (Casey \& Childs, 2011). In addition, exclusive reliance on standardized test results as admission criteria for teacher candidates may provide information on their academic performance. Still, the definitive characteristic of a post-secondary graduate cannot be assessed solely through cognitive competencies (Chao et al., 2019).

Specific to Nigerian teacher education graduates, studies identify that early career teachers possess low pedagogical skills in teaching, ICT, and classroom assessment (Oluwatayo et al., 2014; Omoniyi \& Quadri, 2013). These cannot be dissociated from the entrance criteria used to admit students into teacher education programs (Busayo, 2010). Hence, studies have argued for a limited emphasis on cognitive assessment tools as criteria for post-secondary entrance and education (Casey \& Childs, 2011; Holden et al., 2016). Indeed, other factors (beyond the scope of this paper) account for developing competencies in post-secondary graduates' skills to perform excellently in their chosen careers. Yet, the criteria used to admit candidates into programs may serve as a medium to control entrance and ensure that qualified students are accepted into their desired programs.

\section{Recommendations and Conclusion}

Given the critical analytic stance adopted in this paper, it is pertinent to provide recommendations from post-secondary entrance models from other contexts. These models offer practical suggestions for Nigeria education policy-makers to improve large-scale assessment for entrance into post-secondary programs. 
The 2013 regulatory policy by the Ministry of Education required a structural change to Ontario teacher education programs; hence, adjustments were made to admission practices to effect the changes (Holden et al., 2016). In Ontario, Canada, Holden and colleagues provide a model of admission criteria for selecting teacher candidates into Ontario teacher education programs. In addition to cognitive test results widely used in selecting candidates for teacher education programs across Ontario, most programs adopt non-cognitive admission criteria (Holden et al., 2016). The non-cognitive admission criteria range from written profiles or statements, candidates' experience working with students, recommendation letters, and individual interviews. Although Holden et al. (2016) recommend that since each of the admission criteria used has limitations, a combination of two or three methods would be proper in selecting qualified candidates into teacher education programs. For other non-cognitive assessments (including digital assessment tools) in use, especially among specific Ontario teacher education programs, see Holden et al. (2016).

Another assessment tool developed for teacher candidates in Taiwan is the Situation Judgement Test (SJT). SJT is an assessment tool used to evaluate how prospective teachers can simulate real-life teaching situations. It can be utilized as a supplemental tool to reinforce admission criteria into institutional programs, especially those that have relied mainly on cognitive tests (Chao et al., 2019). Further, SJTs may be designed as paper-based, online, and in video formats. Given its practical design, SJT has proven to enhance the predictive validity of teachers' performance in teacher education programs and in their careers (for a specific example, see a meta-analysis conducted by McDaniel et al., 2001, as cited in Chao et al. 2019). It is important to note that the two post-secondary entrance assessment models discussed here are related explicitly to teacher candidates' recruitment into teacher preparation programs.

So far, this paper has presented a critical overview of the tripartite system employed in the Nigerian post-secondary entrance assessment (the utilization of the SSCE, UTME, and PUTME). An analysis of each examination's assessment policies and design, coupled with results from research studies, implies inadequacies in the assessment system's utility and predictive validity for Nigerian students and graduates. Following some peculiar contextual issues (e. g., students' limited IT skills, limited school facilities to support learning, high examination malpractice rates, etc.) mentioned above, it is highly recommended that education policy-makers urgently review entrance assessment tools. Also, the decadence in the Nigerian education system 
due to its ineffective assessment policies cannot be overemphasized. It is high time that educational policies are revised to accommodate students' procedural and critical thinking skills in national examinations. Therefore, some of the above suggestions, especially the use of cognitive and non-cognitive assessment tools, can be adapted to improve the situation of existing post-secondary entrance examinations in Nigeria.

On a final note, the process of reviewing post-secondary education criteria in Nigeria must begin at all levels of education. For example, the inclusion and enforcement of formative assessment use in early, middle, and senior years will help students develop critical thinking and procedural skills as they progress through K-12 education. When teachers engage students in formative assessment, students become active learners with higher achievement rates, and teachers are less likely to teach to the test (Brown, 2017). Similarly, enforcing the use of formative assessment at all levels of education could encourage examining bodies to reconsider the design of large-scale assessments. Relatedly, the provision of ICT facilities in schools can enhance students' confidence in writing CBT examinations. Regrettably, admitting unsuitable candidates into post-secondary programs due to the inadequacies of the tripartite system of admission may further add to the current problem of unskilled graduates and high unemployment experienced in Nigeria.

In their study of the relationship among Mathematics teacher candidates' recruitment, preparation, and certification in 17 countries, Ingvarson and Rowley (2017) found a positive association between the strength of a country's admission criteria and teachers' future knowledge of content and pedagogy. These authors found that countries with strong teacher quality assurance policies were among the best contenders in international Mathematics tests. Also, teaching and learning pedagogies in countries such as Singapore, Finland, Canada, etc., have contributed to better learning experiences for students. Therefore, with regards to teaching and learning in Nigeria, holistically reviewing admission criteria into teacher preparation programs will ensure that qualified and suitable teachers are graduated and employed to teach students in schools. Similar perspectives may be extended to other university disciplines to improve Nigerian graduates' learning experiences and job competencies.

\section{References}


Abdulkadir, S., \& Ogwueleka, F. N. (2019). Predicting students' first-year academic performance using entry requirements for faculty of science in Kaduna State University, Kaduna, Nigeria. American Journal of Computer Science and Technology, 2(1), 9-21.

Amuche, C. I., Amuche B., Bello, A., \& Marwan, M. B. (2014). A correlational analysis of private and public secondary school students' performance in WAEC and NECO conducted physics examinations. International Journal of Education and Research, 2(10), 407-416.

Brown, G. (2017). Assessment of Student Achievement. New York, NY: Routledge.

Busayo, O. I. (2010). Post-UME screening examination in Nigerian universities: The university of education, Ikere-Ekiti experience. Journal of Educational Focus, 6(2), 1-13.

Casey, C., \& Childs, R. (2011). Teacher education admission criteria as measures of preparedness for teaching. Canadian Journal of Education, 34(2), 3-20.

Chao, T. Y., Sung, Y. T., \& Huang, J. L. (2019). Construction of the situational judgment tests for teachers. Asia-Pacific Journal of Teacher Education, 47, 1-20.

Ebiri, K. (2010). Obasanjo says PUTME should be the basis for admission in universities Guardian, April 13, P. 49

Emaikwu, S. O. (2015). Predictive validity of Unified Tertiary Matriculation Examination (UTME) on Post-Unified Tertiary Matriculation Examination scores (P-UTME) in Nigeria. Asia Pacific Journal of Research, 1(26), 54-64.

Emupenne, O. O. (2017). Integrating the 21st-century skills into the West African Senior School Certificate Examination (WASSCE): Challenges and opportunities. Journal of Educational Assessment in Africa, 12, 224-235.

Federal Ministry of Education, (2004). National Policy on Education. Abuja, NG: Federal Ministry of Education.

Information Nigeria (April 25, 2013). WAEC: Why students fail. Retrieved from https://www.informationng.com/2013/04/waec-why-students-fail.html

Ingvarson, L., \& Rowley, G. (2017). Quality assurance in teacher education and outcomes: A study of 17 countries. Educational Researcher, 46(4), 177-193. 
Post-secondary Entrance Examinations in Nigeria: A Critical Analysis of the Design and Predictive Validity of the Tripartite Assessment System

Joint Admissions and Matriculations Board (2020). Policy meeting: Titbits on 2019 admissions and 2020 UTME. Retrieved from Joint Admissions and Matriculation Board (Jamb.Gov.Ng)

Holden, M., Kitchen, J., Petrarca, D., \& LeSage, A. (2016). Evolving practices: Admissions policies in Ontario teacher education programs. A report prepared for the Department of teacher education, Faculty of Education, Brock University, Canada. Retrieved from https://www.researchgate.net/publication/303485345.

Njoku, J. U., \& Ugochukwu, R. C. (2018). Post Unified Tertiary Matriculation Examination as predictor of students' final degree results. Journal of Research \& Methods in Education, 8(5), 40-46.

Ogechukwu, F. O. (2019). Challenges of 2018 Computer Based Test (CBT) JAMB examination for senior secondary school students' academic performance in Anambra State, Nigeria. European Journal of Education Studies, 6(3), 266-277.

Oluwatayo, G. K., Adirika, B. N., \& Wodi, I. I. (2014). Competencies of Nigerian graduate teachers: The insiders' perspectives. Journal of Emerging Trends in Educational Research and Policy Studies, 5(4), 577-584.

Omoniyi, T., \& Quadri, A. T. (2013). Perceived competence of Nigerian secondary school teachers in the use of Information and Communication Technology (ICT). Journal of Education and Practice, 4(10), 1-8.

Osuagwu, C. M. (2011). Federal Government laments poor performance of students in WAEC. Nigerian Compass, published on November 22, 2011.

Owolabi, H. O., Onuka, A. O. U., Ogunjimi, M. O., Mustapha, Y., Adaramaja, L., \& Daramola, D. (2017). Options functionality of English Language tests for candidates' selection and placement into tertiary institutions in Nigeria: A pilot study. Journal of Educational Assessment in Africa, 12, 265-272.

Sodipo, O. O. (2014). Employability of tertiary education graduates in Nigeria: Closing the skillsgap. Global Journal of Human Resource Management, 2(3), 28-36. 
Terblanche, H. A. (2017). The effective use of multiple-choice questions in assessing scientific calculations. Unpublished Masters Dissertation, University of South Africa, Pretoria, South Africa.

Zwick, R., \& Dorans, N. J. (2016). Philosophical perspectives on fairness in educational assessment. In L. Cook \& N. J. Dorans (Eds). Fairness in educational assessment and measurement, (pp. 267-281). New York, NY: Routledge. 